\title{
A SECOND CASE
}

or

\section{MALFORMATION OF THE LEFT SHOULDER - G IRDLE;}

REMOVAL OF THE ABNORMAL PORTION OF BONE.

WITH

ReMarks ON THE PROBABLe NATURE OF THE DEFORMITY.

\author{
BY \\ ALFRED WILLETT, F.R.C.S., \\ SURGKON TO ST. BARTHOLOMEW's HOSPITAL AND TO \\ HOSPITAL. \\ AND \\ W. J. WALSHAM, F.R.C.S., \\ ASSISTANT SURGEON TO, AND DEMONSTRATOR OF ORTHOPEDIC AND \\ PRACTIOAL SURGKRY AT, ST. BARTHOLOMBW'S HOSPITAL.
}

(Received February 12th-Read March 13th, 1883.)

IN the sixty-third volume of the 'Transactions' is a communication which we had the honour of laying before the Fellows of this Society. It is "an account of a Specimen of Congenital Malformation of the Bony Thorax, Spinal Column, and Left Scapular Arch removed from the body of a woman, thirty-two years old, with remarks on the probable nature of the deformities." The malformation of the shoulder girdle, it may be remembered, con-

voL. LXVI. 
sisted of a triangular bridge of bone stretching between the spinal column and the scapula. Since then a child, ejght years old, with an apparently similar, if not identical, malformation of the left scapular arch has come under the care of one of us (Mr. Willett) at St. Bartholomew's Hospital. The recurrence of a deformity which so recently appeared to be unique, the additional light which we believe it throws upon the nature of the malformation; and the fact that it admitted of successful performance of a surgical operation are our grounds for again bringing the subject under the notice of the Society.

The patient, Violet F., was admitted into Sitwell Ward, July, 1880, for the growing out of the left shoulder blade and lateral curvature of the spine. The mother died of consumption soon after the birth of the child, and the history obtained from the father was unsatisfactory and incomplete. He stated that the child had a nævus at birth; that when two years old she fell and dislocated her left shoulder, and that he, being then in the Army Service Corps, attended to the dislocation himself. Two years later the child hurt the same shoulder when at school. Since that time the deformity of the shoulder has been noticed and is said to be getting worse.

The child (see Plate V) who measures three feet seven inches in height, stands with her body tilted over to the left side, so that the plummet line from the occipital protuberance crosses the posterior superior spine of the ilium, and passes a little internal to the middle line of the left leg. The lumbar anterior curve is nearly normal; the dorsal posterior curve is much diminished, especially at its upper part where it appears almost to be absent. The lower half of the dorsal spine inclines to the right side, the npper half to the left side. The cervical spine inclines to the right. The left scapula is raised one inch higher than the right. Its upper angle, concealed beneath the trapezius, is three inches from the occipital protuberance; its lower angle is opposite the seventh rib which is raised nearly one inch higher than the right. 
Its movements are not as free as those of the right scapula. Such movement as exists takes place at a hinge, which is situated at the junction of the scapula and the abnormal bridge of bone. This process of bone is of a triangular shape with its base attached to the scapula and its apex to the spinal column. It measures about one inch and a half in length and the same in breadth at its base. It tilts the posterior border of the scapula backwards and outwards, so that a prominent ridge is produced where the scapula and process of bone meet. It is at this ridge that the hinge-like movement occurs. The left trapezius is tense and stands out prominently, and immediately beneath its anterior margin is felt the superior border of the scapula. The inner curve of the left clavicle has disappeared, the external curve is prominent. The left arm when raised above the head does not come in contact with the side of the head; the right arm does. The right scapula is normal both as regards position and movement. Its upper angle is four inches in a direct line from the occipital protuberance. Its lower angle is on a level with the seventh rib. The ribs are apparently normal in number on both sides; the intercostal spaces are not increased in width. The shoulder-joints seem normal in all respects.

The operation.-On October 6th, 1880, chloroform having been administered, Mr. Willett made an incision three inches long parallel to the posterior border of the scapula, and another at right angles to it reaching to the spine. The abnormal piece of bone being thus exposed it was separated with the bone-scissors from the scapula, and having been lifted up was severed by bone-forceps from its connections to the spinous processes of the seventh cervical and first dorsal vertebræ. The operation, which was attended with but little hæmorrhage, was performed antiseptically. A drainage-tube having been inserted the edges of the wound were brought together with silver sutures. The patient progressed favorably. On the 13th the drainage-tube was removed and the 
wound appeared almost healed. On the 30th passive movements were begun and the patient was discharged in good health, with some improvement of the shoulder, and with a mechanical support to keep the shoulder in place.

The portion of bone removed at the operation (see Plate VI, fig. 1), has the form of an irregular triangle with a truncated apex by which it had an osseous attachment to the seventh cervical and first dorsal vertebræ. At its base is a layer of cartilage half an inch in thickness by which it was attached to the scapula; the thin lamella of bone seen along the outer border of the cartilage being a part of the scapula itself, which in this situation projected slightly backwards, as it were, to meet the bridge of bone (a wedge-shaped piece of bone has been cut ont from the base for the purpose of microscopical examination). The bone measures, excluding the layer of cartilage, $1 \frac{3}{8}$ inch in length. Its breadth at its base is $1 \frac{1}{4}$ inch ; at its truncated apex $\frac{3}{4}$ of an inch. It varies from a $\frac{1}{4}$ to $\frac{3}{8}$ of an inch in thickness. The layer of cartilage connecting the bone to the scapula forms a gentle curve with its convexity backwards. It was this curve that gave rise to the prominent ridge that existed, as related in the history of the case, at the apparent junction of the bone with the scapuln. The layer of cartilage is slightly thinner at the most prominent part of the curve than where it was connected with the bone or with the scapula. This thinning takes place at the expense of the cartilage on the concave side, so that the appearance of a slight vertical sulcus is produced in this situation. The sulcus is best seen on horizontal section (see Plate VI, fig. 2). It was at this spot that the hinge-like movement before alluded to evidently took place.

The bone, without taking the cartilaginous portion of the specimen into consideration, is slightly concave from base to apex, and nearly flat from above downwards. Its anterior or deep surface, except near the apex where it forms two prominent ridges, an upper and a lower with a deep groove intervening, is flat. The upper and lower 
borders of the bone are rounded, the upper border being slightly expanded where it joined the spine of the seventh cervical vertebra. The bone is covered with periosteum. Muscular fibres are still seen attached to its anterior surface along the line of its junction with the cartilage, and along the outer third of its upper and lower borders. Muscular fibres are also seen attached to the concave surface of the cartilage. These fibres are the remains of the muscles cut through at the operation for the removal of the bone, probably the serratus magnus, levator anguli scapulæ and the rhomboids. On section (see Plate VI, fig. 2) the bone is seen to be composed of cancellous tissue a quarter of an inch in thickness enclosed in a thin outer layer of compact bone. Microscopic examination of a horizontal section carried through the bridge of bone, the intervening cartilage and the portion of scapula removed at the same time shews that ossification was advancing towards the middle of the cartilage from both the bone and the scapula.

Remarks.-That the abnormality of the shoulder girdle in this patient was similar to that in the specimen shown at this Society in 1880 (see 'Transactions' vol. lxiii Plate v), there can, we think, be little doubt. On comparing the portion of bone removed at the operation with the bridge-like piece in the deformed thorax, the resemblance that exists between them is at once apparent. On examination of the second patient before the bone was removed the state of the parts was so similar to that found in the first patient that a diagnosis of a like condition was at once made. At the operation, moreover, the connections of the bone to the spine and to the scapula, seemed, as far as could be made out, identical with those of the bridge-like piece belonging to the deformed thorax.

The occurrence of a similar deformity so soon after the first, which at the time appeared to be unique, is undoubtedly of much interest, especially as we think the slight difference observed in the second case throws additional light on the morphological significance of the abnormality. The difference to which we refer is in the attachment of 
the bone to the scapula in the second case by cartilage. In the first case it will be remembered the attachment was by bone; although a sulcus containing cartilage in the recent state, made it probable that here also the union had at one time been entirely cartilaginous.

In our former communication we may remind the Society we suggested several theories, that seemed to us more or less probable, to account for the presence of the abnormal bridge of bone; and that we classified them according as they could be based upon one or other of the following hypotheses:-1. That the bone was formed in connection with the vertebræ, and afterwards became anchylosed to the scapula. 2. That it was originally a scapular element, and became secondarily fused to the spine. 3. That it was formed independently both of the scapula and the spine.

As the arguments for and against these theories were then discussed at some length we shall not further refer to them, but shall confine our attention to a consideration of the scapular theory which the present case seems to strengthen.

We are inclined then to regard the bridge of bone as an abnormal development of the supra-scapular epiphysis which normally exists as a narrow ridge of bone along the posterior border of the scapula, and consequently as homologous to the supra-scapular bone of some of the lower vertebrata. The points that we think favour such an origin are :-

1st. The apparent continuity in the first specimen of the bridge of bone with the supra-scapular epiphysis of which it appears to be an overgrowth. 2nd. Its cartilaginous attachment in the second specimen to the scapula. 3rd. The absence of analogy between it and any known form of exostosis; and the difficulty of explaining how if it were an exostosis from a vertebra it could have become secondarily attached to the scapula. 4th. The insertion of certain muscles into it showing that the abnormality occurred at a very early period of development. 5th. The 
abnormal condition in the first specimen of the scapula itself ; and the presence of other concomitant malformation of evidently congenital origin.

In our first specimen the bridge of bone is united by its base to the middle third of the posterior border of the scapula. On the posterior aspect this union is osseous, except for an inch above where there is a slight fissure filled in the recent state with soft tissues, and below where the small foramen is now seen. On the anterior aspect this union is cartilaginous, the situation of the cartilage before maceration being now indicated by a sulcus running vertically between the bone and the scapula.

Such a condition of the parts suggests an epiphyseal origin.

Now, along the lower third of the posterior border of the scapula the supra-scapular epiphysis is clearly united, the line of union being indicated by a distinct ridge. On tracing this ridge upwards it appears to be continued into the foramen before mentioned, and through it into the sulcus between the bridge of bone and the scapula; demonstrating, if this be so, that the sulcus itself is a continuation of the epiphyseal line, and that consequently the bridge of bone, which is, moreover, continuous by its lower angle with the united portion of the epiphysis, either is a part of the epiphysis itself greatly over-developed, or if formed from some other source has at least now become intimately blended with the epiphysis. The accompanying drawing (see Plate VI, fig. 3) which represents the condition of the parts is intended to shew these relations. Had the bridge of bone merely become united to the epiphysis some indication of such a union having occurred ought surely to exist; but from the epiphyseal line (the sulcus between the bone and the scapula) to the spinal column the bone appears of one uniform piece and were it not for its spinal attachment, its epiphyseal origin we think could hardly be called in question. We shall refer again to this point, however, later on. Now, that an overgrowth of the supra-scapular epiphysis may occur, is proved, we think, 
by specimens in the Museums of St. Bartholomew's Hospital and of the Royal College of Surgeons. Series A 138 St. Bartholomew's Hospital Museum, is the left scapula from an anencephalous fœetus. An overgrowth of the epiphysis has occurred at the lower third of the posterior border. The opposite scapula presented a like deformity. No. 3287, Royal College of Surgeons' Museum, is a right adult scapula in which a well-marked outgrowth, evidently epiphyseal, has occurred at that part of the posterior border that corresponds to the triangular surface at the base of the scapular spine. Scapulæ showing similar deformities but in a much less degree are not so very uncommon. One is contained in the Museum of St. Bartholomew's. In No.13 normal osteological series, Royal Collegeof Surgeons' Museum (a right scapula and humerus), a well marked outgrowth of the lower third of the supra-scapular epiphysis has occurred and ossification in it has begun. The rest of the epiphysis is normal and not ossified. In No. 65, Teratological series, Royal College of Surgeons' Museum (the skeleton of a fotal kitten) the supra-scapular epiphysis on both sides is apparently prolonged backwards, and is attached to the spine of the second dorsal vertebra. The parts are somewhat shrunken from the action of the spirit. There is no mention of the abnormality of the epiphyses in the account of the specimen in the Catalogue. No. 229 Teratological series, Royal College of Surgeons' Museum is a similar specimen to the preceding.

In the case now before the Society the base of the bridge of bone was united to the middle third of the posterior border of the scapula (which projected backwards, as it were, to meet it) entirely by cartilage. This cartilage consists of a smooth, uniform layer of the same breadth as the bridge of bone on the one hand and the scapula on the other; it is covered on its anterior and posterior aspect by a layer of perichondrium continuous with the periosteum covering the scapula and the bridge of bone; and on section ossification is seen to be advancing towards the centre of the cartilage, from both the bridge 
of bone and the scapula. There is no trace, therefore, in this cartilage of any union having taken place between the cartilaginous border of the scapula and the cartilage of the bone; in other words there is no evidence that the scapula and the bridge of bone have ever been separate. Hence the cartilage in which the bridge of bone was developed would appear to have originally formed part of the general cartilaginous matrix of the scapula. But we know that the osseous material of the bridge was deposited as a centre distinct from that of the body of the scapula since a cartilaginous interval actually exists between them. We have here, therefore, as in the former specimen, all the appearances of the bone being an overgrowth of the epiphysis, but in an earlier stage of development. The osseous union in the elder patient and the cartilaginous union in the younger thus becomes intelligible; for the supra-scapular epiphysis normally unites with the body of the scapula about the twenty-fifth year of life; and as the one patient had reached her thirty-second year and the other had only completed her eighth, we should expect the bridge, were it the epiphysis, to have become united by bone in the former case, and to have remained united only by cartilage in the latter.

If the objection be here raised that the centre of ossification for the supra-scapular epiphysis does not normally appear until about the sixteenth to the eighteenth year, it may be answered that we are not dealing with a case of normal development; and we do not think it at all surprising, seeing the abnormal growth of the cartilage that has taken place, and considering the increased activity of the developmental processes which must have been going on, that ossification should have occurred at an earlier date than usual. We have seen, moreover, that similar instances of early ossification have occurred in the specimens of over-developed epiphysis-one in fœtal life-already alluded to.

Turning now to the vertebral end of the bridge of bone, its firm osseous fusion in both patients to the spines of the 
vertebræ might seem to point to the bone being an exostosis of the spine, which had become secondarily united to the scapula, rather than to its being an abnormal supra-scapular epiphysis. It differs from an exostosis, however, in that it is not covered with cartilage except at the part where it is united to the scapula, in its flattened condition, in its evident growth in only one direction, in its broad base of attachment to the scapula; and in the insertion of muscles into it. Moreover, as far as we know, no case has hitherto been observed of an exostosis springing from one bone and forming an attachment to another bone, by or through its cartilaginous extremity; nor are we acquainted with any physiological or pathological process by which such a union could have been brought about. Lastly, regarded as an exostosis, it furnishes no clue to the concomitant malformation of the scapula and other bones which existed in the first specimen.

Setting aside then the idea of a spinal exostosis, let us consider how, on the assumption of its being an abnormal supra-scapular epiphysis, its intimate fusion to the spine $c: n$ be explained. Now, the epiphysis that normally exists along the posterior border of the scapula in man presents a much higher grade of development in some of the lower animals, and in some even remains separate throughout life as a distinct bone-the supra-scapula. Figs. 4, 5, and 6 in Plate VI represent some of the appearances presented by these parts in different animals. Fig. 4 shows the distinct supra-scapular bone in the shoulder girdle of the frogs and toads, in some species of which it projects so far as to meet its fellow of the opposite side across the middle line of the spine. It is true that the supra-scapular bone is not, as a rule, fused to the spine, but instances of such a union are not wanting, as for example, in the placoid fishes. (See Plate VI, figs. 5, 6.) In fig. 5 a front view of the scapula, supra-scapula, and one of the vertebræ of the skate is represented; fig. 6 is the side view of these parts. Both are copied from Professor Parker's work on the shoulder girdle. 
As the supra-scapular bone then, is admitted by all to be the homologue of the supra-scapular epiphysis of man it, of course, follows that the bridge of bone if it is, as we have tried to show, an abnormal development of the epiphysis must also be the homologue of the supra-scapula of animals. But we have seen that the supra-scapula of animals presents all grades of development, from a mere rudiment to a distinct bone united to the spine as in the skate. We have further seen that the supra-scapular epiphysis in man may actually present an abnormal backward development comparable to that, say, of the rabbit. It is advancing, therefore, but one step further to compare the bridge of bone in our specimen to the distinct supra. scapula of the frog, and but one step further still to con. ceive it united to the spine as in the skate.

If our scapular theory, then, be correct we are no longer met with the difficulty of having to explain how one bone can have become fused to another; for we must regard the bony bridge not as a mere outgrowth or growing backwards of the epiphysis, but as having existed in its present form, though of course in an unassified condition, from the time of the differentiation of the cartilaginous shoulder girdle from the mesoblast; and therefore as having had an attachment to the spine from the earliest period of its development. When we remember how similar in all early vertebrate embryos is the primitive cartilaginous rod from which the shoulder girdle is developed it.would not seem that so very grave a departure from the normal developmental process were required to produce the malformation. We have only to conceive a slight extra-differentiation of the mesoblast in a backward direction to have the primitive cartilaginous rod reaching to the spine. Analogous processes, moreover, are not wanting in the human body, as, for instance, in the not infrequent presence of a cervical rib (as in birds) which as is well known is due to the over development of the anterior part of the transverse process of the seventh cervical vertebra-the homologue of the thoracic ribs; the 
extra differentiation of the mesoblast extending in this instance in a forward direction so that in extreme cases the rib may reach the sternum.

If, therefore, by a forward extension the anterior part of the transverse process-the homologue of a rib-may be developed into an actual rib, as in birds, why may not the epiphysis-the homologue of the supra-scapula-by a similar but backward extension be developed into an actual supra-scapular bone as in fish? If in one case, through extra differentiation, the transverse process of the vertebra may meet the sternum, why in another may not the epiphysis of the scapula through a similar process meet the spine? It is curious that in our first specimen a cervical rib should also have existed.

Given then a cartilaginous union between the scapula and the spine, there is no difficulty in explaining how in the course of development the ossific centres in the spinous process and the supra-scapula, i.e. the bridge of bone, would meet and become ultimately fused, leaving no trace of the former separation any more than in the analogous process of the union of the epiphysis and diaphysis in the development of an ordinary long bone.

The probabilities of the malformation having existed from a very early period are strengthened, we think, by the following facts :-

1st.-The attachment of certain muscles to the bridge of bone. Had it been simply an outgrowth from the spine or from the scapula, i.e. an exostosis, we should have expected to have found the muscles merely displaced by the growth, certainly not inserted into it as they were in both specimens.

2nd.-The rudimentary condition in the first specimen of the scapula itself a fact clearly shewing, theory aside, that some developmental defect has actually occurred in the formation of the shoulder girdle.

3rd.-The concomitant malformations of the spine, ribs and clavicle in the first specimen, which it may be remembered were shewn in our former communication to have 
occurred at a very early period in the development of the embryo.

In conclusion if we admit that the bone is a suprascapula, it would appear that in both of these cases we are dealing with a reversion of the human shoulder girdle to that of a lower type. We confess, however, that we have to seek far down in the scale of animal life before we find its exact homologue; and it may seem improbable that missing so many higher and intermediate forms it should revert to so low a type as that of the skate. These difficulties we think, however, are not greater than those which attend the theory of reversions in general, which theory nevertheless is admitted by most biologists to be the fittest solution for the many similar abnormalities of daily occurrence in the human body.

\section{Note taken 21st February, 1883, of present condition of the patient.}

Front aspect.-Head carried downwards, forwards, and to the left in an oblique direction, the point of the chin being $1 \frac{1}{2}$ inches to the left of the mesial line, and the left ear $1 \frac{1}{4}$ inches above the level of the right. The left shoulder is also rotated slightly upwards and forwards.

Behind.-Scar of operation wound is very sensitive, but otherwise quite natural. Underlying the scar is a dense rounded band of tissue, of the feeling and consistence of muscle, stretching between the upper third of the posterior border of the scapula and the truncated stump of the spinous process, which remains distinctly prominent.

The cervico-dorsal spine is curved to the left, the lower half of the dorsal vertebræ to the right; with corresponding rotatory changes.

Movement of the scapula.-This bone rotates with considerable freedom; however, when the arm is manipulated the upward movement of the arm is checked when it reaches an angle of $145^{\circ}$ with the trunk, apparently being held by the band of tissue above mentioned. 
Those in charge of the child report that she uses the left arm as freely as the right in all respects.

In conclusion it would appear that greatly improved use of the arm has resulted from the operation, but that no appreciable change in the curvature of the spine can be noted.

\section{DESCRIPTION OF PLATES V AND VI.}

Case of Malformation of the Left Shoulder Girdle. (Mr. A. WILLETT and Mr. W. J. WALshaM.)

\section{Plate V.}

The child from whom the piece of bone was removed by Mr. A. Willett. (From a photograph.) Back and front views, before the operation.

\section{Plate VI.}

Fra. 1.-The bridge of bone removed at the operation, front view.

FIG. 2.-Ditto, horizontal section.

FIG. 3.-Condition of parts in 1st specimen (see vol. lxiii, Plate v).

A. The bridge of bone, continuous with :-

B. The united supra-scapulax epiphysis.

c. The body of the scapula.

Fic. 4.-Scapula and supra-scapula of frog. St. Bartholomew's Hospital Museum, S. 28, No. 248.

A. Scapula.

B. Supra-scapula.

Fia. 5.-Scapula, supra-scapula, and vertebra of the skate (from Professor Parker's 'Monograph on the Shoulder Girdle'), front view.

A. The vertebra.

B. The supra-scapula.

c. The scapula.

Fra. 6.-Ditto, ditto, side view. 
3
0
0
0
0
0
0
0
0
0
0
0
0
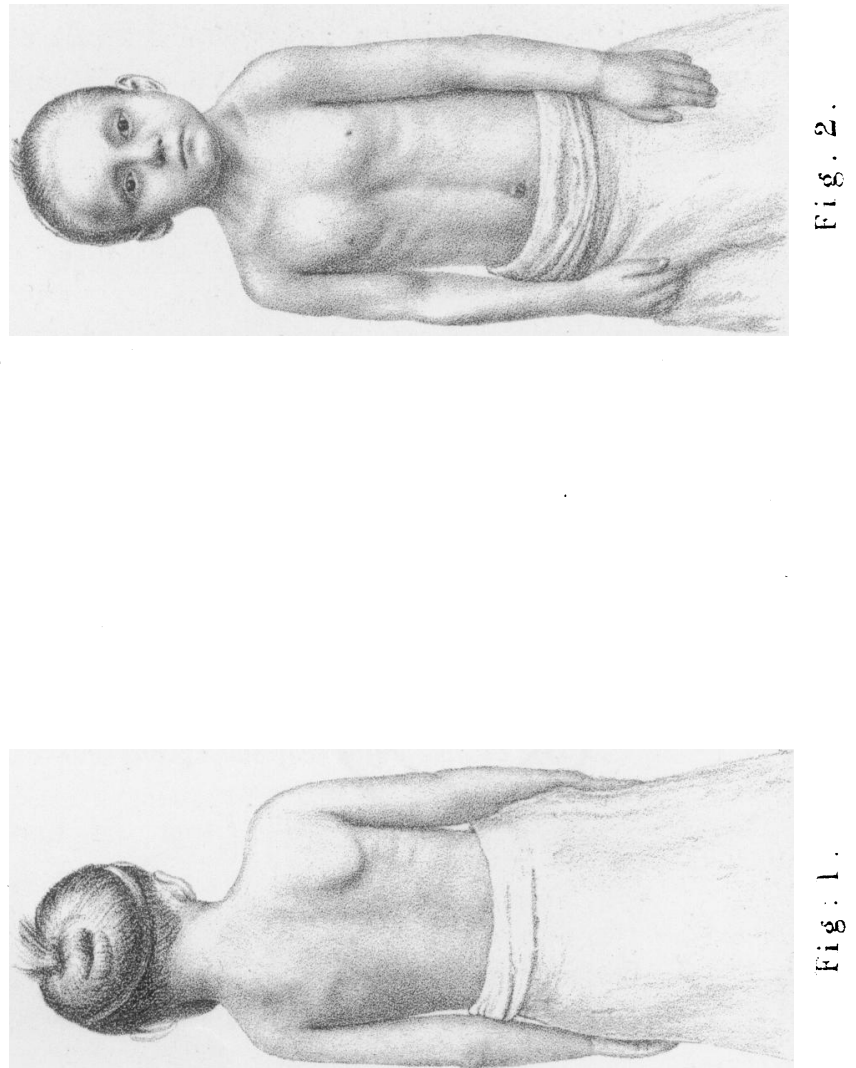


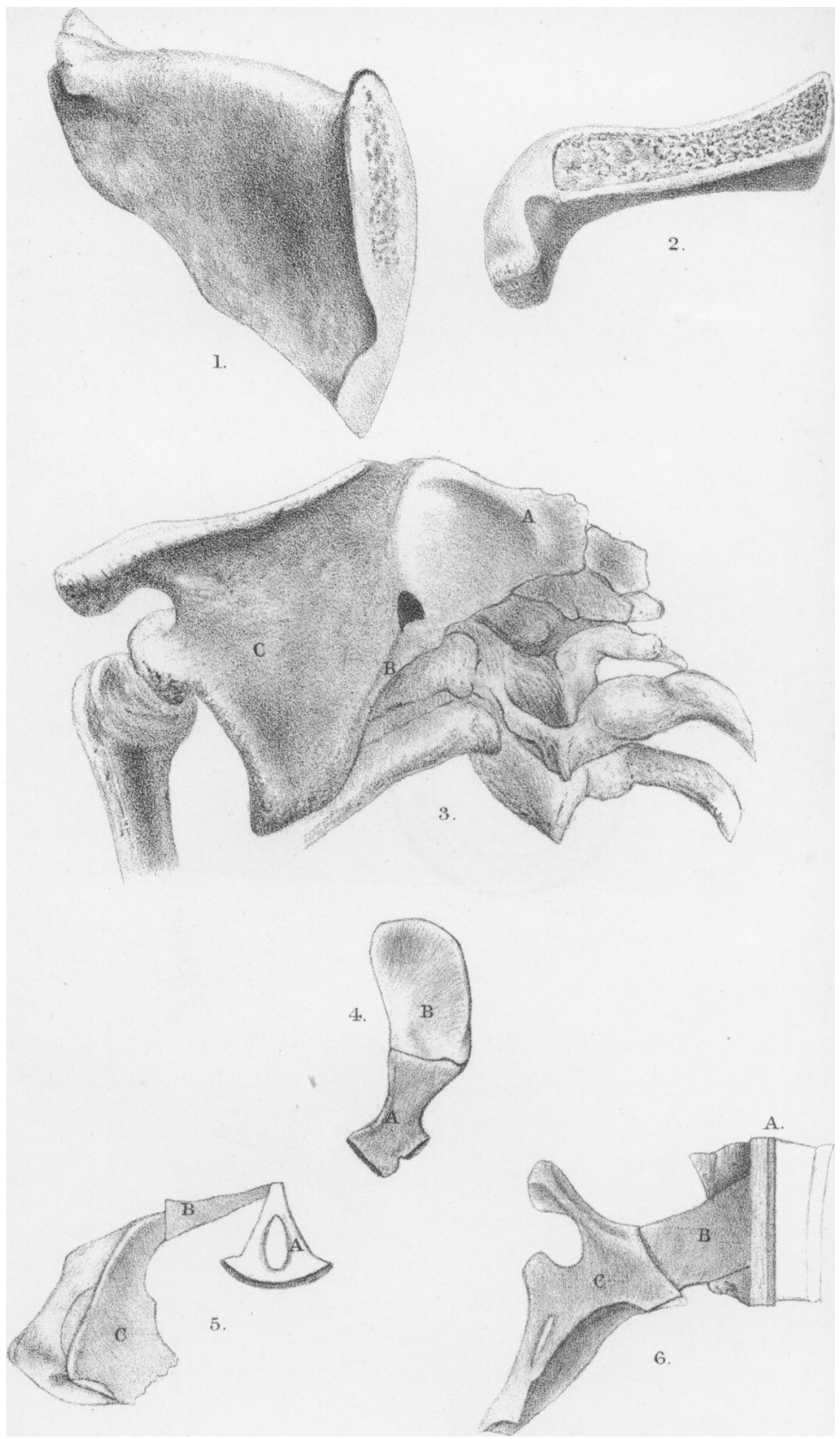

